\title{
Clinical Target Volume in Biliary Carcinoma: A Systematic Review of Pathological Studies
}

\author{
ILARIA MARINELLI ${ }^{*}$, ALESSANDRA GUIDO $^{2 *}$, LORENZO FUCCIO $^{3}$, ANDREA FARIOLI $^{3}$, \\ VALERIA PANNI ${ }^{2}$, LUCIA GIACCHERINI ${ }^{2}$, ALESSANDRA ARCELLI ${ }^{2}$, GIORGIO ERCOLANI $^{3}$, \\ GIOVANNI BRANDI ${ }^{2}$, SILVIA CAMMELLI ${ }^{2}$, ANDREA GALUPPI ${ }^{2}$, GABRIELLA MACCHIA ${ }^{4}$, \\ REZARTA FRAKULLI ${ }^{2}$, GIAN C. MATTIUCCI ${ }^{5}$, FRANCESCO CELLINI ${ }^{5}$, MILLY BUWENGE ${ }^{2}$, \\ MATTEO RENZULLI ${ }^{6}$, FRANCESCO DEODATO ${ }^{4}$, SAVINO CILLA $^{7}$, VINCENZO VALENTINI $^{5}$, \\ VINCENZO TOMBOLINI ${ }^{1}$, RITA GOLFIERI ${ }^{6}$ and ALESSIO G. MORGANTI ${ }^{2}$ \\ ${ }^{1}$ Department of Radiotherapy, Policlinico Umberto I, Sapienza University of Rome, Rome, Italy; \\ ${ }^{2}$ Radiation Oncology Center, Department of Experimental, Diagnostic and Specialty Medicine - DIMES, \\ University of Bologna, Bologna, Italy; \\ ${ }^{3}$ Department of Medical and Surgical Sciences, University of Bologna, Bologna, Italy; \\ ${ }^{4}$ Radiotherapy Unit, General Oncology Unit, and ${ }^{7}$ Medical Physics Unit, \\ Giovanni Paolo II Foundation, Campobasso, Italy; \\ ${ }^{5}$ Department of Radiotherapy, Sacred Heart Catholic University, Rome, Italy; \\ ${ }^{6}$ Radiology Unit, Department of Diagnostic and Preventive Medicine, S. Orsola-Malpighi Hospital, Bologna, Italy
}

\begin{abstract}
Background/Aim: Radiotherapy is a treatment option for both adjuvant and neo-adjuvant settings for biliary tract cancer. Guidelines on the delineation of the target volume of lymph nodes are lacking; only generic indications are available, without specific recommendations for different primary tumour locations (e.g. intrahepatic, extrahepatic biliary tract or gallbladder cancer). The aim of this study was to systematically review available literature to provide recommendations on lymph node target volume delineation in patients with unresectable biliary tumour. Materials and Methods: A systematic search of electronic databases was performed up to July 2016. The primary outcome measure was the rate of lymph node involvement according to the location of primary biliary tumour. Sites with $\geq 5 \%$ of nodal metastases were considered in the clinical target volume for radiotherapy planning. Results: Twelve
\end{abstract}

This article is freely accessible online.

*These Authors contributed equally to this study.

Correspondence to: Alessandra Guido, MD, Ph.D, Radiation Oncology Center, Department of Experimental, Diagnostic and Specialty Medicine, University of Bologna, Via Massarenti 9 , 40138, Bologna, Italy. E-mail: alessandra.guido@aosp.bo.it

Key Words: Lymph node metastasis, biliary tract cancer, clinical target volume, review. studies (1075 patients) were included. The most frequent site of lymph node metastasis in intrahepatic biliary tree carcinoma was retroportal $(61.1 \%$, 95\% confidence interval $(C I)=50.7-70$ $6 \%)$. Other frequently involved lymph nodes were along the hepatoduodenal ligament [frequency $=38.7 \%$, 95\% CI=31.0$47.0 \%]$, those along the common hepatic artery $(17.0 \%, 95 \%$ $C I=8.2-31.9 \%)$ and the hilar nodes $(16.9 \%$, 95\% CI=13.2$21.4 \%)$. In extrahepatic biliary tree cancer, the most frequently involved lymph nodes were the pericholedochal $(42.7 \%, 95 \%$ $C I=33.8-52.1 \%)$ and those along the hepatoduodenal ligament (40.3\%, 95\% CI=32.4-48.8\%). Other commonly involved nodal regions included retroportal lymph nodes $(30.9 \%$, 95\% CI=23.0$40.1 \%)$, pancreaticoduodenal anterior and posterior nodes (30.1\%, 95\% CI=12.2-57.1\%), those along the common hepatic artery $(19.7 \%, 95 \% C I=11.8-31.0 \%)$ and para_aortic nodes (15.2\%, 95\% CI=8.0-27.0\%). The most common site of metastases in gallbladder cancer were the pericholedochal nodes $(25.2 \%, 95 \%$ CI=18.6-33.2\%), those along the cystic duct (23\%, 95\% CI=16.6-30.8\%), and retroportal nodes $(17.1 \%$, 95\% CI=11.6-24.5\%). Conclusion: Biliary tract cancer has a high propensity for regional lymphatic metastases. An evidencebased nodal target definition of biliary tract cancer based on primary tumour location was proposed.

Biliary tract cancer (BTC) is quite rare, representing 3\% of all gastrointestinal tumours (1). BTCs are divided into intrahepatic cholangiocarcinoma, extrahepatic cholangiocarcinoma and, 
finally, gallbladder tumours. These tumours arise from the epithelium lining biliary ducts and the most frequent histological type is adenocarcinoma (90\%) (2). Prognosis is dismal and the only potentially curative option is surgery. Unfortunately, most patients have locally advanced disease at diagnosis and are not suitable for resection. Concurrent chemoradiation is used in both adjuvant and palliative settings (3). In patients with complete resection, the 5-year overall survival rates are 5-10\% for those with gallbladder cancer and those with $10-40 \%$ for cholangiocarcinoma (1). After surgery, patients have a high risk of recurrence, thus justifying the use of adjuvant local treatment. A systematic review showed that adjuvant radiotherapy improves overall survival in those with extrahepatic primary tumour location (4). In particular, patients with positive lymph nodes with/without positive surgical margins experience the greatest benefit (5). Furthermore, chemoradiation represents an important option for locally advanced disease, since it improves the pain control and survival (6).

Modern radiotherapy techniques (three-dimensional conformal radiotherapy-(3D-CRT) and intensity-modulated radiation therapy (IMRT) allow optimal qualitative treatment with reduced toxicity. When planning treatment using these modern radiotherapy techniques, the target volume must be accurately and precisely defined. Despite this, guidelines on the delineation of the target volume of lymph nodes are surprisingly lacking. Only non-specific generic indications not stratified according to the primary tumour location are available (7).

The aim of the current study was to systematically review the available evidence in order to provide practical recommendations for the lymph node target volume delineation in patients with unresectable biliary cancer.

\section{Materials and Methods}

Data sources and search strategy. We performed a comprehensive literature search by using PubMed, SCOPUS, Google Scholar and the Cochrane Library (up to 31st of July 2016) to identify full articles evaluating lymph node involvement in biliary tract cancer. Electronic searches were supplemented by manual searches of references of included studies and review articles.

We identified studies using the following medical subject headings (MeSH) and key words: "biliary tract neoplasms" and "lymph nodes". The search was restricted to English language and full text.

The Medline search strategy was: ("biliary tract neoplasms"[MeSH Terms])OR ("biliary"[All Fields] AND "tract"[All Fields] AND "neoplasms"[All Fields]) OR "biliary tract neoplasms"[All Fields] OR ("biliary"[All Fields] AND "cancer"[All Fields]) OR "biliary cancer"[All Fields]) AND ("lymph nodes"[MeSH Terms] OR ("lymph"[All Fields] AND "nodes"[All Fields]) OR "lymph nodes"[All Fields] OR ("lymph"[All Fields] AND "node"[All Fields]) OR "lymph node"[All Fields]) AND involvement[All Fields].
Eligibility criteria. We included retrospective and prospective human studies. Only studies published in English were included in this review. All studies reporting data on resected biliary tree (intrahepatic, extrahepatic) and gallbladder cancer including lymphadenectomy, independently of the surgical technique in terms of tumour resection and lymph node dissection, were considered eligible. Exclusion criteria were the enrolment in the study of patients who had undergone resection without lymph node dissection and lack of data about the rate of nodal metastases at the different lymph node stations.

Data extraction. For each study, The following data regarding the incidence of lymph node involvement in patients with biliary tree cancer who underwent surgical resection were extracted according to tumour location: number of examined lymph nodes, dissected lymph node stations, and number and site of metastatic lymph nodes. Information about study design, period of enrolment, study location, number of patients, and population characteristics (gender and mean age) were also collected.

Outcome assessment. Primary outcome measures were the rate of lymph node involvement according to the tumour location (as intrahepatic, extrahepatic biliary tract and gallbladder). Based on the lymph node involvement reported in each study, the pooled rates of the involvement of each lymph node station were calculated according to the primary tumour location. Finally, we proposed to include only stations with an incidence of nodal metastases $\geq 5 \%$ in the clinical target volume (CTV) for radiotherapy planning.

Study selection and quality assessment. Three independent researchers (IM, AG, VP) screened citations at the abstract level to identify potentially relevant studies and case series. Potentially eligible citations were retrieved for full-text review, with disagreements resolved by a fourth researcher (AGM). We obtained the following information from each report: author identification, year of publication, number of patients with positive lymph nodes on surgery, number of total examined patients in each article, number of node-positive patients for every lymph node station based on primary tumour location.

Statistical methods. The pooled rate was calculated by dividing the sum of patients with lymph node involvement in a specific lymph node station by the total number of patients with lymph node evaluation of the same station. Proportions were pooled by means of a randomeffects model (8), and then presented as point estimates and $95 \%$ confidence intervals $(\mathrm{CI})$. The main analysis was performed using Comprehensive Meta-Analysis 3.3.070 (Biostat, Englewood, NJ, USA).

\section{Results}

Search results. Through the step of screening the title and the abstract, 35 articles were identified. After full text review, 23 articles were excluded, since they did not report the rate of lymph node stations separately. Therefore, 12 studies were finally included (9-20) The flowchart of the selection process is shown in Figure 1. Of the 12 studies, six were on intrahepatic bile duct tumours (584 patients), four on extrahepatic bile duct cancer (244 patients), and three on gallbladder cancer (247 patients) (one study was on both intraand extrahepatic tumours. Table I shows the characteristics of the included studies. 


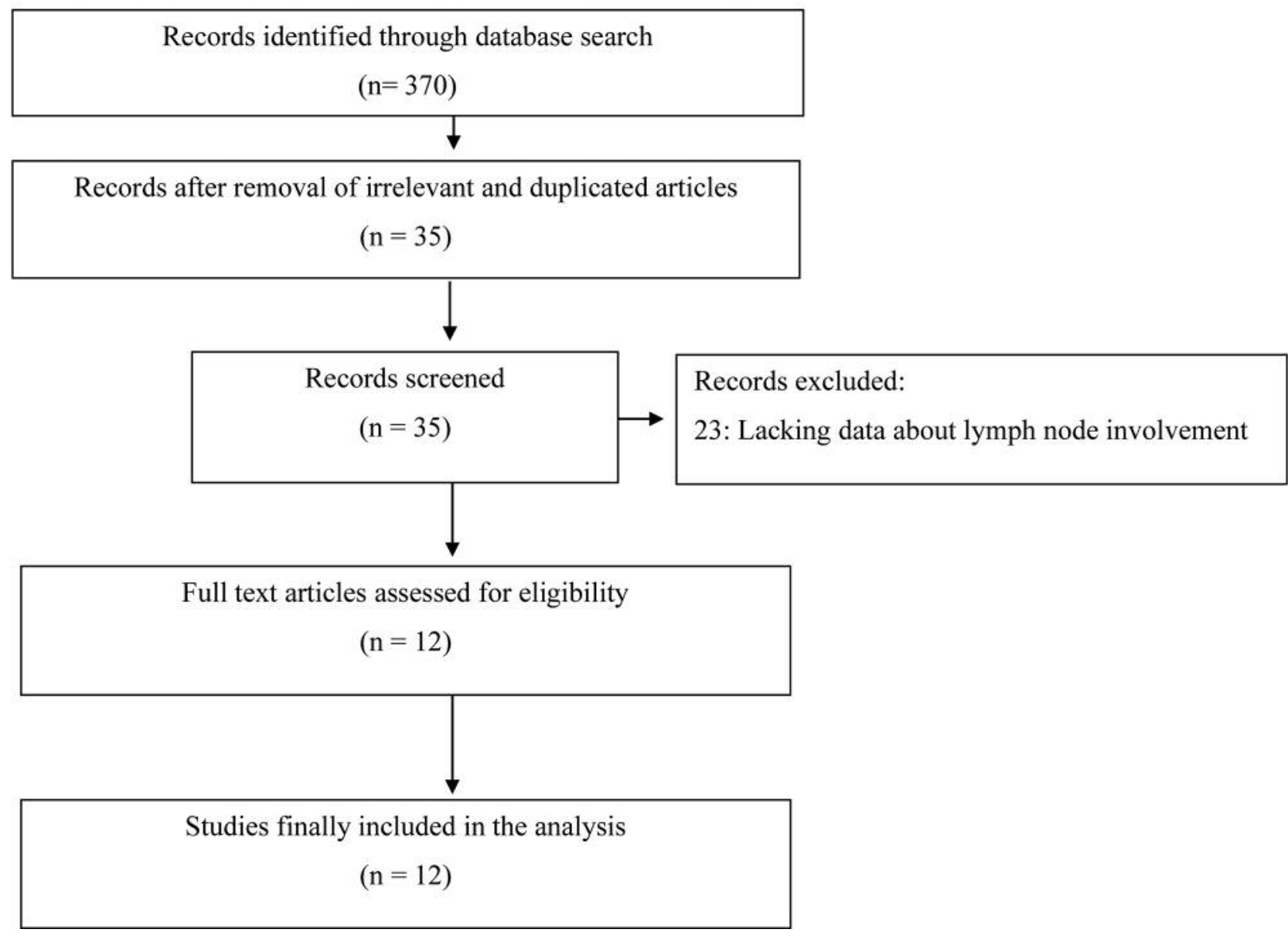

Figure 1. Flow chart of systematic search and review process.

Table I. Study characteristics.

\begin{tabular}{|c|c|c|c|c|c|c|c|c|c|}
\hline Cancer site & $\begin{array}{l}\text { Author, } \\
\text { year } \\
\text { (Ref no.) }\end{array}$ & $\begin{array}{l}\text { Inclusion } \\
\text { period }\end{array}$ & $\begin{array}{l}\text { Study } \\
\text { design }\end{array}$ & $\begin{array}{l}\text { Study } \\
\text { location }\end{array}$ & $\begin{array}{l}\text { Sample } \\
\text { size }\end{array}$ & $\begin{array}{c}\text { Median age }, \\
\text { years }\end{array}$ & $\begin{array}{l}\text { Male } \\
\text { gender, } \\
\text { n }(\%)\end{array}$ & $\begin{array}{l}\text { Median no. } \\
\text { of LNs } \\
\text { dissected per } \\
\text { patient (range) }\end{array}$ & $\begin{array}{c}\text { Patients } \\
\text { with } \\
\text { lymph node } \\
\text { metastases }\end{array}$ \\
\hline \multirow[t]{6}{*}{ Intrahepatic } & Tsuji et al., 2001 (9) & $1980-1998$ & Retrospective & Japan & 39 & $58.7(41-76)$ & $27(69 \%)$ & $32(10-49)$ & $62.0 \%$ \\
\hline & Nagakawa et al., 2005 (10) & $1983-2004$ & Retrospective & Japan & 30 & NS & NS & NS & $43.0 \%$ \\
\hline & Yamamoto et al., 1999 (11) & 1980-1996 & Retrospective & Japan & 51 & NS & NS & NS & $45.0 \%$ \\
\hline & Guglielmi et al., 2013 (12) & 1990-2012 & Retrospective & Italy & 54 & NS & NS & $55(1-33)$ & $33.3 \%$ \\
\hline & Jiang et al., 2010 (13) & 1999-2008 & Retrospective & China & 90 & NS & $52(58 \%)$ & NS & $93.3 \%$ \\
\hline & Chen et al., 2011 (14) & $2000-2010$ & Retrospective & China & 320 & $57(18-99)$ & $184(58 \%)$ & NS & $23.8 \%$ \\
\hline \multirow[t]{4}{*}{ Extrahepatic } & Guglielmi, et al., 2013 (12) & $1990-2012$ & Retrospective & Italy & 72 & NS & NS & $79(1-27)$ & $41.7 \%$ \\
\hline & Yoshida et al., 1999 (15) & 1983-1998 & Retrospective & Japan & 42 & $64(35-78)$ & $28(67 \%)$ & $320(21-48)$ & $60.0 \%$ \\
\hline & Yoshida et al., 1998 (16) & 1995-1996 & Retrospective & Japan & 20 & NS & NS & NS & $55.0 \%$ \\
\hline & Kitagawa et al., 2001 (17) & 1983-1998 & Retrospective & Japan & 110 & $601(24-78)$ & $80(73 \%)$ & 241 & $52.7 \%$ \\
\hline \multirow[t]{3}{*}{ Gallbladder } & Negi et al., 2011 (18) & 2003-2009 & Retrospective & India & 57 & $46(42-58)$ & $13(23 \%)$ & NS & $58.0 \%$ \\
\hline & Kondo et al., 2002 (19) & 1982-1999 & Retrospective & Japan & 112 & $64(33-82)$ & $41(37 \%)$ & NS & $58.9 \%$ \\
\hline & Liu et al., 2013 (20) & $1995-2010$ & Retrospective & China & 78 & $59(33-82)$ & $32(41 \%)$ & $4(1-24)$ & $47.4 \%$ \\
\hline
\end{tabular}

LN: Lymph node; NS: not specified. 

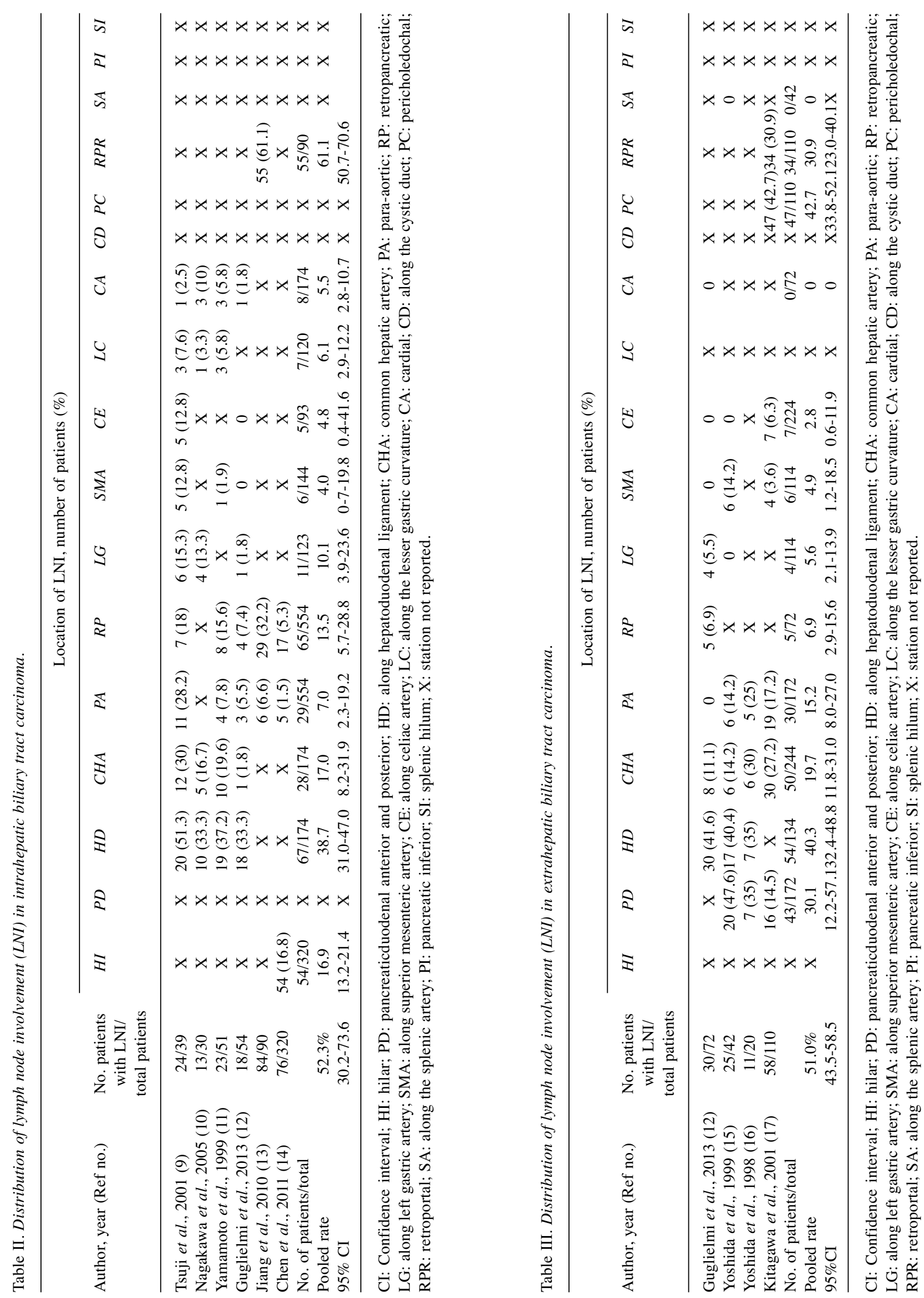
Recommendations for target definition. Details on the rates of lymph node station involvement in patients with intra-, extrahepatic and gallbladder neoplasms are reported in Tables II, III and IV, respectively. Based on these estimates, Table $\mathrm{V}$ reports the lymph node stations that should be included in delineation of nodal target volume according to the tumour location.

Intrahepatic biliary cancer. The following lymph node stations should be included in the target volume: retroportal (frequency $=61.1 \%, 95 \% \mathrm{CI}=50.7-70.6 \%$ ), those along the hepatoduodenal ligament $(38.7 \%, 95 \% \mathrm{CI}=31.0-47.0 \%)$, along the common hepatic artery $(17.0 \%, 95 \% \mathrm{CI}=8.2-$ $31.9 \%)$, hilar lymph nodes $(16.9 \%, 95 \% \mathrm{CI}=13.2-21.4 \%)$, retropancreatic $(13.5 \%, 95 \% \mathrm{CI}=5.7-28.8 \%)$, left gastric artery $(10.1 \%, 95 \% \mathrm{CI}=3.9-23.6 \%)$, para-aortic $(7.0 \%, 95 \%$ $\mathrm{CI}=2.3-19.2 \%)$, lesser gastric curvature $(6.1 \%, 95 \% \mathrm{CI}=2.9-$ $12.2 \%)$ and cardial nodes $(5.5 \%, 95 \% \mathrm{CI}=2.8-10.7 \%)$. Celiac trunk and nodes along superior mesenteric artery lymph nodes should be excluded from the target volume because they were found to be involved in fewer than $5 \%$ of cases.

Extrahepatic biliary cancer. The following lymph node stations should be included in the target volume: pericoledochal (frequency $=42.7 \%, 95 \% \mathrm{CI}=33.8-52.1 \%$ ), those along the hepatoduodenal ligament $(40.3 \%, 95 \% \mathrm{CI}=32.4-48.8 \%)$, retroportal lymph nodes $(30.9 \%, 95 \% \mathrm{CI}=23.0-40.1 \%)$, pancreatico-duodenal anterior and posterior $(30.1 \%, 95 \%$ $\mathrm{CI}=12.2-57.1 \%)$, along the common hepatic artery $(19.7 \%$, $95 \% \mathrm{CI}=11.8-31.0 \%)$, para-aortic $(15.2 \%, 95 \% \mathrm{CI}=8.0-27.0 \%)$, retropancreatic $(6.9 \%, 95 \% \mathrm{CI}=2.9-15.6 \%)$ and those along the left gastric artery $(5.6 \%, 95 \% \mathrm{CI}=2.1-13.9 \%)$. Celiac trunk and nodes along superior mesenteric artery lymph nodes should be excluded from the target volume because they were found to be involved in fewer than $5 \%$ of cases.

Gallbladder cancer. The following lymph node stations should be included in the target volume: pericoledochal (frequency $=25.2 \%, 95 \% \mathrm{CI}=18.6-33.2 \%$ ), along cystic duct $(23.0 \%, 95 \% \mathrm{CI}=16.6-30.8 \%)$, retroportal lymph nodes (17.1\%, 95\% CI=11.6-24.5\%), along the common hepatic artery $(15.8 \%, 95 \% \mathrm{CI}=10.3-23.2 \%)$ and those along the hepatoduodenal ligament $(13.4 \%, 95 \% \mathrm{CI}=8.2-21.0 \%)$, retropancreatic $(12.3 \%, 95 \% \mathrm{CI}=6.0-23.6 \%)$, pancreaticduodenal anterior and posterior $(7.7 \%, 95 \% \mathrm{CI}=3.5-16.1 \%)$, para-aortic $(6.0 \%, 95 \% \mathrm{CI}=1.0-78.3 \%)$ and hilar lymph nodes $(5.1 \%, 95 \% \mathrm{CI}=1.9-12.9 \%)$.

\section{Discussion}

Surgical resection remains the most important treatment for patients with BTC, but despite improvements in surgical techniques and adjuvant treatments, resected biliary 
Table V. Lymph node stations to be included or excluded in delineation of nodal target volume according to tumour location.

\begin{tabular}{|c|c|c|c|c|c|c|c|c|c|c|c|c|c|c|c|c|c|}
\hline \multirow[b]{2}{*}{ Tumour location } & \multicolumn{17}{|c|}{ Lymph node station } \\
\hline & $\mathrm{HI}$ & $\mathrm{PD}$ & HD & $\mathrm{CHA}$ & $\mathrm{PA}$ & $\mathrm{RP}$ & LG & SMA & $\mathrm{CE}$ & $\mathrm{LC}$ & $\mathrm{CA}$ & $\mathrm{CD}$ & $\mathrm{PC}$ & RPR & SA & PI & SI \\
\hline IHBT & $\mathrm{Y}$ & $\mathrm{N}$ & $\mathrm{Y}$ & $\mathrm{Y}$ & $\mathrm{Y}$ & $\mathrm{Y}$ & $\mathrm{Y}$ & $\mathrm{N}$ & $\mathrm{N}$ & $\mathrm{Y}$ & $\mathrm{Y}$ & $\mathrm{N}$ & $\mathrm{N}$ & $\mathrm{Y}$ & $\mathrm{N}$ & $\mathrm{N}$ & $\mathrm{N}$ \\
\hline EHBT & $\mathrm{N}$ & $\mathrm{Y}$ & $\mathrm{Y}$ & $\mathrm{Y}$ & $\mathrm{Y}$ & $\mathrm{Y}$ & $\mathrm{Y}$ & $\mathrm{N}$ & $\mathrm{N}$ & $\mathrm{N}$ & $\mathrm{N}$ & $\mathrm{N}$ & $\mathrm{Y}$ & $\mathrm{Y}$ & $\mathrm{N}$ & $\mathrm{N}$ & $\mathrm{N}$ \\
\hline GB & $\mathrm{Y}$ & $\mathrm{Y}$ & $\mathrm{Y}$ & $\mathrm{Y}$ & $\mathrm{Y}$ & $\mathrm{Y}$ & $\mathrm{N}$ & $\mathrm{N}$ & $\mathrm{N}$ & $\mathrm{N}$ & $\mathrm{N}$ & $\mathrm{Y}$ & $\mathrm{Y}$ & $\mathrm{Y}$ & $\mathrm{N}$ & $\mathrm{N}$ & $\mathrm{N}$ \\
\hline
\end{tabular}

IHBT: Intrahepatic biliary tract; EHBT: intrahepatic biliary tract; GB: gallbladder; Y: Yes; N: No; HI: hilar; PD: pancreaticduodenal anterior and posterior; HD: along hepatoduodenal ligament; CHA: common hepatic artery; PA: para-aortic; RP: retropancreatic; LG: along left gastric artery; SMA: along superior mesenteric artery; CE: along celiac artery; LC: along the lesser gastric curvature; CA: cardial; CD: along the cystic duct; PC: pericholedochal; RPR: retroportal; SA: along the splenic artery; PI: pancreatic inferior; SI: splenic hilum.

neoplasms still locally recur at a high rate, and in patients not suitable for resection, local progression represents the main cause of death (21). Park and colleagues showed that more than $60 \%$ of patients with resected extrahepatic biliary cancer had llocoregional recurrence (22). Jung and coworkers reported even higher locoregional recurrence rates, of $70 \%, 86 \%$, and $57 \%$, in patients with gallbladder, intrahepatic, and extrahepatic cancer, respectively (23).

Several retrospective studies have shown that chemoradiation can improve local control and overall survival in selected patients in both adjuvant and neoadjuvant settings (3-5). Unfortunately, these data derived from retrospective series and therefore future prospective randomized trials are necessary to confirm these results. In the past, radiotherapy of abdominal tumors was limited by the tolerance of organs at risk. IMRT technique and imageguided radiation therapy can deliver radiation doses to the target while sparing surrounding organs. Thus, these emerging techniques are expanding the treatment of BTC. Recently, it was shown that IMRT of BTC achieved safe dose escalation without dose-limiting toxicity (24). With the advent of these new techniques, the accurate definition of the tumour target volume and of draining lymph nodal areas that should be prophylactically irradiated is crucial. Standardized guidelines for target definition for prophylactic nodal irradiation are currently lacking.

Areas at higher risk for local relapse are generically identified as nodes along the porta hepatis, pancreaticoduodenal system and celiac axis, however no specific indications in published literature are available. Therefore, our systematic review was performed in order to identify the lymph node stations mainly involved according to primary tumour location and to provide a practical tool for radiotherapists for target volume delineation.

Interestingly, the study of Guglielmi et al. found that the most frequently involved lymph node station, in both intrahepatic and extrahepatic tumour locations, was along the lymph nodes of the hepatoduodenal ligament (12). Moreover, all patients with positive lymph nodes in other regions (such as cardial and celiac trunk, along gastric artery, common hepatic artery, pancreaticduodenal and along superior mesenteric artery lymph nodes) always had involvement of the hepatoduodenal ligament lymph node station. Therefore, since this station does not appear to be 'skipped' during the metastatic process, it should be considered an obligatory step.

Our study has certain limitations. Despite our data being derived from surgical series, sampling of all the lymph node stations was not always performed, therefore our information is partially incomplete. Furthermore, we were unable to give indications about which lymph node stations should be included in the target volume based on the different extrahepatic subsites (i.e. Klatskin or distal choledochal neoplasms) because these kind of data were lacking. Moreover, our findings cannot suggest target modulation based on clinical tumour and nodal stages. The chosen cutoff $(5 \%)$ for inclusion in the target may seem rather low. However, our study addresses even advanced tumors, in which the incidence of nodal metastasis is probably higher than the incidence reported in surgical series, obviously including less advanced cancer.

This systematic review was based on pathological studies in patients who underwent resection, but more information could come from studies of patterns of failure aimed at analyzing the sites of relapse of primary tumour and nodal stations after radiochemotherapy, using systematic imaging monitoring.

In conclusion, we have proposed an evidence-based nodal target definition in BTC based on the site of primary tumor (namely intrahepatic, extrahepatic or gallbladder) that could represent a practical and useful tool for radiotherapists.

\section{Conflicts of Interest}

No actual or potential conflicts of interest exist regarding this article. 


\section{References}

1 Eckel F, Brunner T and Jelic S: Biliary cancer: ESMO Clinical Practice Guidelines for diagnosis, treatment and follow-up. Ann Oncol Suppl 6: vi40-44, 2011.

2 Vatanasapt V, Sriamporn S and Vatanasapt P: Cancer control in Thailand. Japan J Clin Oncol 32: S82-S91, 2002.

3 Macdonald $\mathrm{OK}$ and Crane $\mathrm{CH}$ : Palliative and postoperative radiotherapy in biliary tract cancer. Surg Oncol Clin N Am 11: 941-954, 2002.

4 Bonet BM, Allal AS, Gich I, Solè JM and Carriò I: Is adjuvant radiotherapy needed after curative resection of extrahepatic biliary tract cancers? A systematic review with a meta-analysis of observational studies. Cancer Treat Rev 38(2): 111-119, 2012.

5 Horgan AM, Amir E, Walter T and Knox JJ: Adjuvant therapy in the treatment of biliary tract cancer: a systematic review and meta-analysis, J Clin Oncol 30: 1934-1940, 2012.

6 Ghafoori AP, Nelson JW, Willett CG, Chino J, Tjler DS, Hurwitz HI, Uronis HE, Morse MA, Clough RV and Czito BG: Radiotherapy in the treatment of patients with unresectable extrahepatic cholangiocarcinoma. Int J Radiat Oncol Biol Phys: 81(3): 654-659, 2011.

7 Deodato F, Clemente G, Mattiucci GC, Macchia G, Costamagna G, Giuliante F, Smaniotto D, Luzi S, Valentini V, Mutignani M, Nuzzo G, Cellini N and Morganti AG: Chemoradiation and brachytherapy in biliary tract carcinoma: long-term results. Int J Radiat Oncol Biol Phys 64(2): 483-488, 2006.

8 DerSimonian R and Laird N: Meta-analysis in clinical trials. Control Clin Trials 7(3): 177-188, 1986.

9 Tsuji T, Hiraoka T, Kanemitsu K, Takamori H, Tanabe D and Tashiro D: Lymphatic spreading pattern of intrahepatic cholangiocarcinoma. Surgery 129: 401-407, 2001.

10 Nagakawa T, Kamiyama T, Kurauchi N, Matsushita M, Nakanishi K, Kamachi H, Kudo T and Todo S: Number of lymph node metastasis is a significant prognostic factor in intrahepatic cholangiocarcinoma. World J Surg 29: 728-733, 2005.

11 Yamamoto M, Takasaki K and Yoshikawa T: Lymph node metastasis in intrahepatic cholangiocarcinoma. Jpn J Clin Oncol 29: 147-150, 1999.

12 Guglielmi A, Ruzzenente A, Campagnaro T, Valdegamberi A, Bagante F, Bertuzzo F, Conci S and Iacono C: Patterns and prognostic significance of lymph node dissection for surgical treatment of perihilar and intrahepatic cholangiocarcinoma. J Gastrointest Surg 17(11): 1917-1928, 2013.

13 Jang W, Zeng Z, Tang Z, Fan J, Zhou J, Zeng MS, Zhang JY, Chen YX and Tan YS: Benefit of radiotherapy for 90 patients with resected intrahepatic cholangiocarcinoma and concurrent lymph node metastases. J Cancer Res Clin Oncol 136: 13231331, 2010.
14 Chen YX, Zeng ZC, Tang ZY, Fan J, Zhou J, Jiang W, Zeng MS and Tan YS: Prediction of the lymph node status in patients with intrahepatic cholangiocarcinoma: analysis of 320 surgical cases. Front Oncol 1: 42, 2011.

15 Yoshida T, Shibata K, Yokoyama H, Morii Y, Matsumoto T, Sasaki A and Kitano S: Patterns of lymph node metastasis in carcinoma of the distal bile duct. Hepatogastroenterology 46 : 1595-1598, 1999.

16 Yoshida T, Aramaki M, Bandoh T, Kawano K, Sasaki A, Matsumoto T, Morii Y and Kitano S: Para-aortic lymph node metastasis in carcinoma of the distal bile duct. Hepatogastroenterology 45(24): 2388-2391, 1998.

17 Kitagawa Y, Nagino M, Kamiya J, Uesaka K, Sano T, Yamamoto $\mathrm{H}$, Hyakawa $\mathrm{N}$ and Nimura Y: Lymph node metastasis from hilar cholangiocarcinoma: audit of 110 patients who underwent regional and para-aortic node dissection. Ann Surg 233: 385392, 2001.

18 Negi SS, Singh A and Chaudhary A: Lymph nodal involvement as prognostic factor in gallbladder cancer: Location, count or ratio? J Gastrointest Surg 15: 1017-1025, 2011.

19 Kondo S, Nimura Y and Kamiya: J Mode of tumor spread and surgical strategy in gallbladder carcinoma. Langenbecks Arch Surg 387(5-6): 222-228, 2002.

20 Liu GJ, Li XH, Chen YX, Sun HD, Zhao GM and Hu SY: Radical lymph node dissection and assessment: Impact on gallbladder cancer prognosis. World J Gastroenterol 19: 51505158,2013

21 Kang YJ, Heo SH, Kim JW, Shin SS, Chang NK and Choi S: Detection of intra-abdominal tumor recurrence in patients with cholangiocarcinoma: comparison of contrast-enhanced MDCT and 18F FDG-PET/CT. J Korean Soc Radiol 62: 149-157, 2010.

22 Park SW, Park YS, Chung JB, Kang JK, Kim KS, Choi JS, Lee VJ, Kim BR and Song SY: Patterns and relevant factors of tumor recurrence for extrahepatic bile duct carcinoma after radical resection. Hepatogastroenterology 51: 1612-1618, 2004.

23 Jung SJ, Woo SM, Park HK, Lee VJ, Han MA, Han SS, Kim SH, Park SJ, Kim TH, Koh YH and Hong EK: Patterns of initial disease recurrence after resection of biliary tract cancer. Oncology 83: 83-90, 2012.

24 Fuller CD, Dang ND, Wang SJ, Desai P, Choi M, Thomas CR Jr. and Fuss M: Image-guided intensity-modulated radiotherapy (IG-IMRT) for biliary adenocarcinomas: Initial clinical results. Radiother Oncol 92: 249-254, 2009.

Received December 12, 2016

Revised February 1, 2017

Accepted February 7, 2017 